\title{
Age as a factor in sensory integration function in Taiwanese children [Corrigendum]
}

\author{
LinCK, WuHM, WangHY,Tseng MH,LinCH.Neuropsychiatric
}

Disease and Treatment. 2013;9:995-1001.

On page 997, second sentence of the Instrument section, reads "The TSIF subtests are as follows: (1) Postural Movement (12 items); (2) Bilateral Integration Sequences (16 items); (3) Sensory Discrimination (eleven items); (4) Sensory Modulation (21 items); (5) Sensory Seeking (nine items); (6) Attention And Activity Levels (18 items); and (7) Emotional Behavior (eleven items)." ${ }^{22}$ should have been "The TSIF subtests are as follows: (1) Postural Movement (12 items); (2) Bilateral Integration Sequences (16 items); (3) Sensory Discrimination (eleven items); (4) Sensory Modulation (21 items); (5) Sensory Seeking (nine items); (6) Attention and Activity Levels (18 items); and (7) Emotional Behavior (eleven items). ${ }^{.22}$

On page 997, fourth sentence of the Instrument section, reads "Teachers of the participants scored each behavior, as follows: $1=$ never (the child never responds in this fashion when presented with the opportunity [0\% of the time]); $2=$ seldom (the child responds occasionally in this fashion [25\%]); $3=$ occasionally (the child responds sometimes [50\%]); $4=$ frequently $[\geq 75 \%] ; 5=$ always (the child responds in the manner noted every time when presented with the opportunity [100\%])." should have been "Teachers of the participants scored each behavior, as follows: $1=$ never (the child never responds in this fashion when presented with the opportunity [ $0 \%$ of the time]); $2=$ seldom (the child responds occasionally in this fashion [25\%]); $3=$ occasionally (the child responds sometimes [50\%]); $4=$ frequently [75\%]; $5=$ always (the child responds in the manner noted every time when presented with the opportunity [100\%])."

\section{Publish your work in this journal}

Neuropsychiatric Disease and Treatment is an international, peerreviewed journal of clinical therapeutics and pharmacology focusing on concise rapid reporting of clinical or pre-clinical studies on a range of neuropsychiatric and neurological disorders. This journal is indexed on PubMed Central, the 'PsycINFO' database and CAS
The manuscript management system is completely online and includes a very quick and fair peer-review system, which is all easy to use. Visit http://www.dovepress.com/testimonials.php to read real quotes from published authors. 